\title{
«Nosotros éramos el tercer mundo y teníamos que imponer ese ideal justicialista» Violencia política y nacionalismo en la biografía de un obrero peronista*
}

\author{
«We Were the Third World and We Had to Impose that Justicialist Ideal.» \\ Political Violence and Nationalism in the Biography of a Peronist Worker \\ CAMILLO ROBERTINI \\ Consejo Nacional de Investigaciones Científicas y Técnicas \\ Instituto de Investigaciones Gino Germani, Universidad de Buenos Aires (Argentina) \\ https://orcid.org/0000-0001-8111-8526 \\ camilo.robertini@gmail.com
}

\begin{abstract}
Resumen
Este artículo es un acercamiento a la biografía de un sindicalista perteneciente a la derecha peronista durante los años 70. A través de una historia de vida, nos proponemos abordar la memoria, el imaginario y la historia de un sindicalista y obrero común. En el artículo se recurre a la metodología de la Historia oral y al género biográfico para abarcar algunos problemas fundamentales de la historia reciente argentina: la formación de la identidad política peronista, los rasgos del sindicalismo "vandorista" y la formación de sindicalistas de la llamada derecha sindical. A través de este estudio, se aborda una temática poco estudiada en los trabajos sobre movimiento obrero, es decir la existencia de una cultura político-sindical férreamente anticomunista. El análisis de esa cultura política, gravitante en el mundo de la derecha peronista, pretende brindar un estudio de caso inherente a la relación entre derechas y mundo del trabajo durante los años 70 .
\end{abstract}

Palabras clave: Argentina, sindicalismo, historia oral, memoria.

\section{Abstract}

This article approaches the biography of a trade unionist belonging to the Peronist right wing during the 1970s. Through a life story, we propose to analyze the memories, imaginary, and story of a common trade unionist and worker. The article draws from oral history methodology and the biographical genre to cover some fundamental problems of the recent Argentine history: the conformation of the Peronist political identity, the traits of "vandorist" trade unionism, and the emergence of the

\footnotetext{
* Una primera versión de este artículo fue presentada como ponencia en el III Workshop historia de la juventud: nacionalismos cotidianos, emociones e identidades. Argentina, 1955-1978, el 12 de noviembre de 2019. Agradezco los comentarios de Bettina Favero, Juan Luis Besoky e Xosé Núñez Seixas.
} 
trade unionists of the so-called syndicalist right wing. This study approaches a largely unexplored aspect of the labor movement: the existence of a strongly anti-communist politico-syndicalist culture. The analysis of this political culture, crucial in the world of right-wing Peronism, aims to provide a case study inherent to the relationship between right-wing movements and the working world during the 1970s.

Keywords: Argentine, unionism, syndicalism, oral history, memories.

\section{INTRODUCCIÓN}

El campo de estudios de la historia reciente en Argentina ha acumulado, en los últimos años, una valiosa cantidad de estudios referidos a los años sesenta y setenta (Águila et. Al., 2018), (Águila 2013), (D’Antonio \& Eidelman, 2013). La investigación acerca del pasado reciente se ha concentrado en el análisis de las experiencias militantes, en la historia de la represión perpetrada por las fuerzas armadas y en la trayectoria de las organizaciones de los derechos humanos (Franco, Águila, Garaño, Scatizza, 2016). La historia del movimiento peronista, en particular, ha brindado nuevos puntos de vista e interpretaciones en lo que respecta al período comprendido entre 1955 y 1976. Una tendencia cada vez más presente en la historiografía se relaciona con el análisis de la experiencia de las derechas y del nacionalismo como parte de las dinámicas socio-históricas referidas al pasado reciente (Besoky, 2013), (Bohoslavsky, Sá Motta, Boisard, 2019), (Cerrano, Ghiretti, 2018). Es así que, en los últimos años, se ha superado un prejuicio metodológico, el de estudiar las derechas como si se tratara de un objeto monolítico, y se ha comenzado a pensarlo en sus aspectos plurales, discontinuos y contradictorios, llegando a estudiar los sentimientos y las memorias de los perpetradores de delitos de lesa humanidad.

En este contexto, sobre todo los estudios que han toman en cuenta el problema de las juventudes y de la participación de jóvenes de las asociaciones, organizaciones, partidos políticos de la galaxia del nacionalismo argentino, han cobrado particular relevancia, (Manzano, 2010 y 2017), (Bartolucci, 2017), (Favero, 2016). Pese al predominio del interés de los especialistas por la historia de las organizaciones obreras, revolucionarias y foquistas, las contribuciones que han puesto énfasis en el mundo de las derechas y del nacionalismo argentino están cobrando cada vez más importancia.

En este ensayo nos referimos a "derecha" apuntando a la "derecha peronista", entendida como el conjunto de las organizaciones y movimientos políticos de inspiración reaccionaria que, sobre todo a raíz de la llamada Revolución Libertadora (1955), se nuclearon alrededor del peronismo proscripto. Consideramos que la derecha peronista fue, entre los años 60 y 70, un amplio espacio político dominado por una visión de la realidad marcada por el anticomunismo y por un rotundo repudio de cualquier manifestación de modernización de la realidad nacional (Besoky, 2013).

Es oportuno resaltar que, en el marco de los estudios del trabajo, luego de una larga etapa -a nivel global- marcada por el paradigma del llamado «nacionalismo metodo- 
lógico» y por el interés casi exclusivo por las organizaciones de izquierda, ha cobrado relevancia la problemática de la filiación de los trabajadores a movimientos políticos y sindicales no necesariamente revolucionarios (Van Der Linde, 2019) ${ }^{1}$.

El trabajo que proponemos se coloca en este contexto, marcado por nuevos interrogantes y desafíos de investigación, y por nuevas contribuciones que están dibujando un pasado reciente no solamente dominado por las organizaciones de tendencia revolucionaria.

El objeto de este ensayo es la biografía de un sindicalista y obrero argentino, joven durante los años sesenta, y su trayectoria político-social. A través de su historia de vida, la de una persona “común" de la década del sesenta y setenta, de extracción obrera, pretendemos reconstruir su memoria, subjetividad e imaginario. Recurrir a la historia de vida de Alexander resulta fundamental para abordar algunas cuestiones referidas a la formación de un joven nacionalista que transitó por movimientos como Tacuara y Fuerzas Armadas Peronistas, y que desembocó en una larga trayectoria entre la Unión Obrera Metalúrgica y sus patotas sindicales (Ladeuix, 2012), (Zicolillo, 2013), (Padrón, 2007), (Cucchetti, 2013).

La identidad del joven nacionalista es el eje de este trabajo. Entendemos por identidad política al conjunto de valores y elementos morales capaces de determinar un perfil político que, en el contexto de la Guerra Fría y de la vigencia de la grandes ideologías del siglo XX. Veremos que, en el caso de Radic, su biografía fue determinante para configurar una identidad política particular, que lo llevó a involucrarse en los rangos de las organizaciones de la derecha peronista. Cabe resaltar que, si bien consideramos una trayectoria individual, ésta puede extenderse también a muchos jóvenes de la misma época, que compartían los mismos valores y la misma visión del mundo (Passerini, 2007).

En las siguientes páginas, analizaremos con mayor atención dos momentos fundamentales presentes en la historia de vida del nacionalista argentino: su juventud, marcada por la filiación de los padres al Partido Justicialista y los acontecimientos conectados al levantamiento antiperonista de la llamada Revolución Libertadora y a la formación intelectual y al pensamiento de un peronista de extrema derecha, y, por último, la representación de la violencia ejercida en contra de las organizaciones revolucionarias durante los años 70 .

Este trabajo se basa en la realización de distintas entrevistas a Alexander Radic ${ }^{2}$ y en la frecuentación de personalidades relacionadas al mundo de la derecha sindical

1 Es así que, en países europeos en los cuales históricamente permanecía una visión de la clase obrera muy esquemática, en la cual los trabajadores eran víctimas de la represión y protagonistas de estallidos sociales revolucionarios, se ha resaltado el papel de las organizaciones y sindicatos no comunistas. El caso de España aparece emblemático, con referencia a la participación del sindicalismo "vertical" al régimen de Franco (Sánchez Recio, 2002), (Soto Carmona, 2006) también como el de Italia, en el cual la historiografía, luego de 1989, ha comenzado en reflexionar acerca de los "obreros sin clase" (Musto, 2015)

2 Es un seudónimo. 
argentina. Si bien el caso que expondremos se refiere a un individuo y a su realidad extremadamente subjetiva y por eso mismo irrepetible y peculiar, el análisis de su biografía, de su micro-historia, nos brinda informaciones e interpretaciones a través de las cuales es posible abordar temas y problemas que trascienden el exclusivo caso subjetivo. Como la historia oral y la microhistoria han planteado en varias ocasiones, el género biográfico en historiografía ofrece la concreta posibilidad de formular análisis y conclusiones capaces de abarcar una realidad que trasciende el caso específicamente tratado (Portelli, 2007), (Portelli, 2017), (James, 2004). De esta manera, la memoria de un sujeto no nos habla solamente acerca de la de este individuo, sino también de la vivencia de su grupo familiar, de las personas con las cuales compartió espacios de sociabilidad y del conjunto de individuos que representan el entramado de relaciones y afectos presente en su cotidiano (Bourdieu, 1986).

Las entrevistas a Alexander fueron realizadas en el marco de una investigación más amplia (Robertini, 2019) y representan más de ocho horas de grabaciones, a las cuales se suman documentos de la época aportados por el mismo entrevistado y distintas comunicaciones llevadas adelante a través de las redes sociales. De este conjunto documental, utilizaremos solamente una parte, con el objetivo de analizar el papel de la juventud en la formación de un nacionalista argentino de la década del 60 y la naturalización de las prácticas violentas. De esta forma, seguiremos la biografía de Alexander desde un punto de vista cronológico, si bien los dos temas de nuestro interés aparecen en distintos momentos de la autorepresentación del joven nacionalista.

\section{«El 17 de octubre era la llama que se me prende a mí» LOS PRIMEROS AÑOS, LA RESISTENCIA PERONISTA Y EL PENSAMIENTO NACIONAL}

La primera entrevista que realicé en la casa de Alexander fue marcada por un elemento que en un segundo momento entendí también por su valor simbólico: la persistencia y la centralidad la historia del grupo familiar, la filiación al primer peronismo, el carácter obrero de su familia que, casi inconscientemente, justificaría una trayectoria de vida en el nacionalismo argentino y en el peronismo de derecha.

La historia de la familia Radic se coloca entre las dos guerras mundiales, en el límite entre Italia y el entonces reino de Yugoslavia. Luego de la ocupación de Pola por parte de las tropas italianas, comenzaron las persecuciones de las colectividades eslavas allí presentes. El señor Radic, como muchos compatriotas, decidió irse a América en busca de un futuro más seguro. Alexander se detuvo en los detalles acerca de estos hechos durante la primera entrevista, y se esforzó por subrayar la "pureza" étnica de su familia, una de las tantas de rusos en Argentina.

Mi papá croata que se comió la guerra del '14, cuando tenía 17 años vino acá a la Argentina, no sabía leer ni escribir, mi papá, entonces se casaron, mi mamá tenía 26 años, 
mi papá 36, mi papá vino acá de Pola y se fue a San Antonio de Areco a trabajar. [...] Era más gaucho que yo. Y mi padre era un croata loco, era. Era un gaucho, yo tengo el poncho de mi papá. Asado, vino, no le toques eso a mi viejo porque te mataba, era más argentino que yo te digo, era una cosa de locos, el mate... ${ }^{3}$

La identidad de la familia yugoslava, como se puede observar a través de la entrevista, se articula sobre un doble registro: por un lado, a través de la reivindicación del ser croata, del pertenecer a un país en el cual entre las dos guerras se formaron movimientos de derecha como el Ustasha, y por el otro llamando en causa la argentinización del padre, etapa fundamental en la autorepresentación de Alexander como nacionalista y argentino.

En el relato de Alexander, los primeros años y la breve infancia tienen un lugar protagónico en la reproducción ordenada y regular de su biografía. En la memoria del joven se entrecruzan informaciones, recuerdos y memorias que, si bien no ha vivido, son parte del entramado de anécdotas, cuentos y recuerdos del conjunto familiar. Los recuerdos de la Primera guerra mundial, de la llegada al Río de la Plata, de la Argentina peronista aparecen, con toda la fuerza del mito fundador, en el recuerdo del entrevistado. Es el mito que articula un papel fundamental en la "justificación" de la militancia del joven nacionalista en las filas del peronismo de base.

Los padres de Alexander se conocen en una fábrica de Buenos Aires y fundan, con un grupo de compañeros, un núcleo sindical que, a partir de 1955, intenta organizarse para resistir a la desperonización de la Argentina.

El ruido de las bombas sobre la Plaza de Mayo y de los fusilamientos de los trabajadores a favor del general Valle no fueron oídos por Alexander y, sin embargo, son parte de aquella historia compartida por muchos argentinos sobre la cual se edifica su biografía.

Le hacen la revolución a Perón, 16 de septiembre de 1955, a los dos días, se hace una reunión en mi casa, esos recuerdos vagos que tiene uno, yo me acuerdo... [que] dos días después de la revolución en casa aparecen 8, 10 personas... mesita y el mate. Ahí hablando todos, y yo iba y venía, escuchaba [...] Y lo que me acuerdo perfectamente como si estuviéramos ahora es que uno dice: no te hagas problema, yo con la bicicleta les voy a avisar a todos los muchachos.

¿Qué era lo que pasaba? Al otro mes era el 17 de octubre, y ¿qué estaban haciendo estas personas en casa? Estaban organizando lo que iba a ser el 17 de octubre, el 17 de octubre era la toma de la fábrica, no dejar entrar a trabajar a nadie y hacer los piquetes [...] y bueno, el que quería entrar a trabajar, no entraba, porque no entraba, se iba desnudo a la casa, era terrible, era terrible. Entonces yo ahí voy hilvanando cómo van sucediendo las cosas políticamente... a los pocos días del golpe de Estado se forman los Soldados de Perón, que eran como células barriales...

3 Entrevista a Alexander Radic (seudónimo), Tres de Febrero (prov. de Buenos Aires), 8-6-2018. 
Bueno, y yo creo que el 17 de octubre era la llama que se me prende a mí, ¿por qué? porque no solamente pasó el 17 de octubre, no pasó eso, después vinieron los otros temas que como empezaron a apretar a los obreros había paros y todos los líos salían de la noche. Entonces yo, 11 años, 12, ¿cuál era mi tarea? decía mi mamá a las 6 de la mañana salía mi papá, a las 6 de la mañana salía mi papá, decía 'andá hasta la fábrica a ver si a papá lo meten preso', entonces ¿qué hacía? Por ejemplo, estaba la fábrica, la puerta, venían 10, 20 camiones de policía estos que lo encierran ¿viste? lo ponían de culata y la gente salía y se subían arriba de... directamente a la comisaría iban todos. Entonces yo llegaba a mi casa: 'mamá, tenemos que ir a buscar a papá a la comisaría' 4 .

Los recuerdos de la militancia sindical de los padres, de las reuniones de los primeros núcleos que conformaban la resistencia peronista, ocupan un lugar importante en la autorepresentación de Alexander. El reconocimiento de que el primer peronismo fue una época de oro, la filiación de la familia con las organizaciones obreras, su ayuda en la identificación del padre frecuentemente preso por razones gremiales, representan la base sobre la cual el entrevistado edifica su identidad. Remarcar en la actualidad -cuando la mayor parte de su vida ha transcurrido- estas historias que se ubican en los años de la infancia, se puede leer como el intento de hacer más coherente y lineal una trayectoria de vida que por su propia naturaleza muy raramente tiene un desarrollo ordenado (Portelli, 2007: 349). Las teleologías que se encuentran a menudo en las autorepresentaciones de los entrevistados demuestran el papel que el deseo y la imaginación juegan en la construcción de las identidades políticas y de los sujetos (Passerini, 2017).

El período 1955-1973, marcado por la prescripción del peronismo y por la inestabilidad del sistema político argentino, es el contexto en el cual el joven hijo de yugoslavos se va formando (James 1990). De acuerdo a la época Alexander, quien cultivaba la expectativa de encontrar un trabajo más estable, consigue un empleo como matricero en un tallercito de barrio con 13 años de edad. El contexto de la "desperonización" de la sociedad argentina, marcado por el intento simbólico y material de borrar la experiencia de los gobiernos justicialistas (Sigal y Verón, 2003), hace que el joven Alexander se acerque a una agrupación cuyo objetivo es transformar la Argentina en un país "sano", sin banqueros ni judíos y alejado de la izquierda.

Entonces a los 16 años ingreso a un grupo nacionalista, Tacuara.

ROBERTINI: Ah...

Que se llamaba, vos mira cómo son las cosas que decían que Perón estaba en contra de los curas, en contra de estos, en contra de aquellos... la sigla era Dios, Patria y Hogar, la sigla de Tacuara.

4 Entrevista a Alexander Radic (seudónimo), Tres de Febrero (prov. de Buenos Aires), 8-6-2018. 
Nos reuníamos. Había por todos lados y cuando venía el que... [...] Ezcurra Uriburu, un cura, y antes de empezar las reuniones rezábamos el Padre Nuestro, antes de empezar las reuniones. ${ }^{5}$

El rápido paso por Tacuara marca un período de aprendizaje fundamental en la trayectoria posterior del militante peronista. En la agrupación de la ultraderecha, Alexander se dedica al estudio y a la práctica de piquetes, asaltos y otras acciones de tipo violento. Si bien su militancia se da en una organización urbana, muy a menudo integrada por los hijos de la clase media, su condición obrera se refleja en el interés que va madurado por las cuestiones gremiales, por la filosofía y el pensamiento sindical elaborado por el peronismo (Torre, 2012), (Cerrano, 2014).

La militancia y después los libros ¿viste? Los libros es una cosa esencial [...] José Luis Torres, Jauretche, Fermín Chávez. Y hay un montón, hay un montón de gente. Antes de Perón [que pensaba como él], imaginate vos que Perón sale a la palestra política en 1943 con el GOU, que uno dice Grupo de Oficiales Unidos [que] eran todos coroneles. Y José Luis Torres, yo tengo un libro que es de 1933, pero si vos no leés, vos lo leés y decís 'es Perón, es Perón éste'. Scalabrini Ortíz, que era socialista.

Perón decía que nosotros teníamos, no que pelear, sino que disponer de nuestro tiempo para hablar de un tercer mundo, alejado tanto de una política de derecha como de la izquierda, nosotros éramos el tercer mundo y teníamos que imponer ese tipo de ideas justicialistas y justicia social que está parado o apoyado en la doctrina social de la Iglesia. Eso es lo que debería ser, ese es el pensamiento.

Nuestro panteón era constituido por San Martín, Rosas, Perón. San Martín por la independencia. Rosas es por la soberanía política y Perón por la justicia social.

[Este era mi pensamiento nacional] después podemos hablar de Sarmiento que le pidió la Baring Brothers Rivadavia que lo terminó pagando Perón en 1947... yo me cansé de leer, yo escribí en contra de Sarmiento diez, diez... textos.

Pero ¿por qué? Porque me leí todos los libros de Sarmiento, cómo pensaba este hijo de puta. Éste no quería las islas Malvinas, no quería el estrecho de Magallanes, la Patagonia tenía que ser chilena. Ese es un reventado y después lo nombran acá, dicen ¿cómo es que le dicen? El primer gran maestro... no servía ni para caca ese tipo. Hay otro, Almafuerte, hay otros mucho más superiores, Avellaneda.

Hay que razonar, hay que sentarse, hay que leer aquel, hay que leer al de allá. Y después, por eso te dije de entrada, yo te dije a mí, mi viejo y mi vieja me enseñaron 'Perón y Evita', sí, Perón y Evita pero ¿por qué?, y hay que pensar bien, hermano. Hay que leer, había que pensar en una política económica nacional y una soberanía política y una justicia social, ¿quién va a estar en contra de eso? Si todos queremos una nación justa, libre y soberana, como decía Perón ${ }^{6}$.

5 Entrevista a Alexander Radic (seudónimo), Tres de Febrero (prov. de Buenos Aires), 8-6-2018.

6 Entrevista a Alexander Radic (seudónimo), Tres de Febrero (prov. de Buenos Aires), 8-6-2018 
Durante su breve juventud, Alexander se dedica a leer algunos textos que se transformarán en los pilares de su identidad política. Los clásicos del pensamiento nacionalista de las décadas del 40-60 y la producción escrita de Juan Perón y Evita, sobre todo los tomos que componen la Doctrina peronista y La razón de mi vida. Durante una de las dos entrevistas que se habían llevado a cabo en su casa, ubicada en un barrio popular del Gran Buenos Aires, el mismo Alexander había hecho particular hincapié en la centralidad que habían jugado aquellos textos no solamente en la etapa de su formación como adulto, sino también en distintos momentos de su vida. También por este motivo, en la segunda entrevista, una vez que había apagado el grabador, se había preocupado por mostrarme su colección de libros y apuntes, recitándome algunos aforismos significativamente subrayados.

La maduración de una postura firmemente nacionalista, antiliberal y anticapitalista, que revindicaba la centralidad del Estado, se refleja también en la peculiar forma de mirar a las relaciones laborales y del papel del sindicato. La idea según la cual la Argentina, tarde o temprano se hubiese debido transformar en un Estado nacional-sindicalista, como aquel teorizado por Primo de Rivera en España, explica la necesidad del joven nacionalista de participar en la "transformación" del Estado a partir de su militancia gremial.

\section{«Tiene tantas faces el peronismo, tan abierto es, que puede entrar cualquiera: el chorro, el asesino, el marxista» IDENTIDAD POLÍTICA Y VIOLENCIA SINDICAL}

A mediados de los años sesenta, luego de salir de la experiencia en Tacuara, Alexander se incorpora a un grupo sindical vinculado a las Fuerzas Armadas Peronistas (FAP) (Canosa Mora, 2017). Tuvo un paso breve por esta agrupación, durante el cual se suma a los grupos de rompehuelgas. Por divergencias ideológicas con su célula, progresivamente siempre más cercana a la izquierda, Alexander rompe con las FAP y se acerca al peronismo ortodoxo.

En Caseros, una localidad obrera de la periferia del Gran Buenos Aires, se acerca al sindicalismo peronista y experimenta las prácticas violentas del patoterismo sindical. Comienza a trabajar en una industria automotriz del Gran Buenos Aires, la Fiat Concord, y allí se vincula con personalidades y sindicalistas que responden al secretario de la Unión Obrera Metalúrgica, Augusto Timoteo Vandor. En esa etapa, dominada por la proscripción del peronismo impulsada por la dictadura de la autodenominada Revolución Argentina (1966-73), el núcleo obrero de Alexander se organiza alrededor de la Agrupación Azul y Blanca, cuyos principales objetivos eran discutir con la empresa la mejora de los sueldos y beneficios sociales y organizar el partido peronista todavía en clandestinidad. Un eje particularmente importante, como recuerda el testimonio, giraba en torno a aquellas iniciativas que pretendían mantener vivo el recuerdo del gobierno de Perón como, por ejemplo, las misas con las cuales se recordaba cada año la muerte de Evita. 
El convenio, cuando entré, era ganar 4 con 20 y ganaba 4 con 20 , y nadie discutía nada, viste, bueno, ¿qué pasa? Empezamos a entrar gente de Vandor [...] Nosotros ya estábamos militando por el Partido peronista. No nos dejaban hacer la misa de Evita, los curas no te querían hacer la misa de Evita, no había ningún cura. Y se empezaron a hacer las misas, las primeras misas, acá en San Martín a una cuadra.

La Iglesia, y me acuerdo que cuando salimos de la misa estaba toda la caballería de la policía que te pegaban con unos palos así de largos, nos mataron a palos... Hasta que después un padre de acá que ayudaba mucho a los pobres, les daba de comer, todo, un padre obrero, empezó a hacer las misas y le importó un corno que venga la policía, no le importó nada.

Bueno, ahí empezamos la azul y blanca, se llamaba Agrupación Azul y Blanca, nada más.

ROBERTINI: Ustedes marxistas no eran...

No. No. Pero a ver, a ver, yo soy marxista y él me invita a una agrupación peronista y yo me prendo y agarro la doctrina y hablo como un peronista y me olvido que fui marxista, sos peronista. Es así [...] tiene tantas faces el peronismo, tantas faces, tan abierto es, tan abierto que puede entrar cualquiera, el chorro, el asesino, entra cualquiera al peronismo, entra cualquiera, es así. El peronismo es así, yo no te digo viste que... En todos los partidos, en todos los partidos hay de todo ${ }^{7}$.

En el contexto de la dictadura de Juan Carlos Onganía, las relaciones laborales se tensan cada vez más. Por un lado, la opción perfilada por Vandor, la de un "peronismo sin Perón" y, por el otro, el surgimiento de la izquierda clasista, modificaron las relaciones en las fábricas, complicando la existencia de aquellas grandes empresas que, bajo el empuje del desarrollismo, habían llegado a Argentina con la perspectiva de producir sin deber lidiar con la fuerza de trabajo.

La mejora de las condiciones de vida experimentadas por aquellos sectores del mundo del trabajo que accedieron a un puesto estable, son indudables. La generación de Alexander, hija de la última migración europea, gracias a las grandes industrias, experimentó una estabilidad económica hasta poco tiempo antes inimaginable. Para algunos, el frágil estatus alcanzado fue la base para construir las plataformas contestatarias de la década del 60; para otros, un fetiche a defender contra cada intento de modificar la realidad social de la época. En la fábrica en la cual opera Alexander, el sindicalismo vandorista se impone sobre la base obrera, ofreciendo, a cambio de súper explotación y orden, buena remuneración y servicios sociales de alto nivel (Robertini, 2019).

A partir de esta constatación, que se hizo evidente en distintos momentos de la entrevista, Radic me bridó documentación y fotografías alusivas a una supuesta «linda época de la fábrica», que hacían evidentes la gratitud y el reconocimiento de uno de los tantos trabajadores a la gran empresa fordista. 
El énfasis que había hecho en esa disposición positiva hacia la gran empresa tiene una fuerte presencia en su memoria -más allá de una real filiación y cercanía a las lógicas empresarias-, como herramienta discursiva para justificar, a partir de los hechos del Cordobazo, su rotunda alteridad respeto de las formaciones sindicales de la izquierda. La consideración de aquel momento de movilizaciones sociales inéditas en la historia argentina como algo «desastroso» y de las izquierdas como un enemigo, ajeno al ser nacional, tomó forma a la hora de definir aquella coyuntura como si se tratara de una «guerra» (Franco, 2012).

Yo apoyo el pensamiento de los militares, [...] Yo, si me tenía que pelear, agarrar a piñas, tirar tiros, lo hacía a las 2 de la tarde y a las 5 de la mañana, a mí no me importaba. Y yo no gané todas las batallas, ¿sabes cuántas veces vine marcado a mi casa? Me mataban a palos. Me mataban a palos.

ROBERTINI: Bueno, no sé la Fiat, pero sé que en general eran las fábricas quienes entregaban...

No sé, mirá, a mí nunca la fábrica me dijo 'éste'. A mí, que yo era el que estaba metido, que yo metido en la lucha contra el ERP y Montoneros, a mí nunca la fábrica me dijo 'éste'. Nunca.

ROBERTINI: Bueno, pero era también evidente que...

Pero los olíamos nosotros. Ahora ¿por qué? Yo te voy a confesar algo acá: Viene [un compañero] y dice 'Che', dice, 'Tengo un pibe... 'Peludo' le decía yo porque tenía el pelo por acá, y se hacía los claritos ¿¿Un hombre con claritos?! Dice, «me comentan que se reúnen en José C. Paz〉, dice, 〈Una gente de izquierda.〉 Le digo 〈Anotamelo.〉 Ya sabían quién era yo, ¿viste? Yo estaba en todos los despelotes. [...]

ROBERTINI: Pero ¿vos qué tenías, una patota, algo así? Una cosa informal, digamos...

No, una cosa informal era. No, yo no tenía un regimiento de nada... Yo les avisaba a los muchachos nada más, les digo 'Che muchachos, van a repartir los volantes hoy a las 3 de la mañana.' ‘YY cómo sabes vos?'. 'Y... me dijeron' ${ }^{8}$.

La autorepresentación y la memoria de Alexander se pueden leer dentro de una tensión propia de la Guerra fría, en la cual las identidades políticas de los sujetos se van construyendo como si se tratara de espejos. El joven nacionalista de la década del 70 es anticomunista y antirrevolucionario, ya que en aquel contexto político-social existían estas tendencias. El surgimiento de una identidad binaria, de un nosotros/los otros, es fundamental en la articulación de la autorepresentación de nuestro entrevistado y también a la hora de determinar la «velocidad» de su narración. Si las referencias a su contempo- 
raneidad, a los últimos años, fueron rápidas y circunstanciales y marginales en el total de más de 8 hs de entrevistas -los recuerdos de su infancia y su participación como miembro de una patota sindical ocupó un lugar mucho más extenso. Estas diferencias de velocidad son significativas. Si bien no se puede encontrar el "porqué" de estas diferencias, podemos suponer que su decisión de insistir en relatar su participación en las organizaciones de la derecha sindical peronista hoy, le genera orgullo, nostalgia por ese período (Portelli, 2007: 7). A la satisfacción determinada por el poder relatar por primera vez y detalladamente los mecanismos de una patota sindical, acompañaba el tétrico goce que generaba en Alexander toda referencia a eventos violentos, enfrentamientos y asaltos.

Un día en la puerta de la fábrica están repartiendo los volantes y le digo ‘¿Me das uno?' Con la mano izquierda se lo pedí.

Le digo 〈¿Me das uno?〉〈No〉. 〈Dámelo〉. 〈No〉. Le saco uno, le saqué uno así y 'la comisión directiva, vende obreros'. Le digo «Escuchame, acá no podés repartir esto, dámelo〉. 〈No〉. 〈Dámelo〉. 〈No〉. 〈Dámelo〉. 〈No〉. Y me dice: ¿¿Qué sos, matón de Rucci?〉 Me dice. 〈Pero por qué no te vas a la puta que te parió vos, Rucci y Stalin〉. Le pegué acá así... Lo agarré así de abajo, lo maté, Camilo, lo quería despertar, no se despertaba, yo decía lo maté. Lo maté ${ }^{9}$.

En un volante de la izquierda clasista de la fábrica de Alexander, que bien podría tratarse de aquel al cual hizo mención en el relato anterior, podemos leer que:

Lo que la patronal desea es seguir embolsando miles y miles de millones de pesos a costa de nuestro sudor y sacrificio.

Lo que Ordoz y su camarilla [de la Azul y Blanca] pretenden es seguir - como hasta ahora lo han hecho mediante el fraude, el matonaje y la delación - sirviendo de la mejor manera posible a esta política sin que le mueven [sic.] el piso ${ }^{10}$.

Leyendo los testimonios documentales de la época, aparece con toda su fuerza la cuestión de las prácticas violentas llevada a cabo por los miembros de la Agrupación Azul y Blanca y los constantes enfrentamientos (Besoky, 2016a), (Besoky, 2016b). Resulta pertinente destacar la relación que se establece entre los hechos violentos de los 70 y la actualidad. En muchos casos, es posible leer la intención de los protagonistas de matizar y minimizar su propia participación en hechos violentos del pasado (Albornoz, 2019). Esa tendencia se justifica a la luz de la visión estigmatizante de aquellos hechos vistos desde el hoy. Sin embargo, a medida que iba avanzando la entrevista, tuve la impresión de que el elemento violento presente en muchos relatos del militante peronista representa uno de los pilares identitarios alrededor de los cuales se construye su subjetividad. El amor por el riesgo, la exaltación de la violencia sin límites y el imaginario macho que cons-

9 Entrevista a Alexander Radic (seudónimo), Tres de Febrero (prov. de Buenos Aires), 20-10-2018.

10 Seguir el ejemplo de Sitrac-Sitram, Volante de Política Obrera, 1969. 
truía a través de las palabras, eran testimonios de una identidad forjada en el escenario político de las décadas del 60 y 70. Al mismo tiempo, el riesgo constituido por ser parte de la represión paraestatal en contra de «la subversión marxista» caracteriza aún más su imaginario político y su identidad política, que gravita alrededor de la derecha peronista y del pensamiento nacionalista apreciable en publicaciones como «El Caudillo» (Besoky, 2010), (Bohoslavsky y Vicente, 2014).

Yo puse en riesgo la vida de mis hijos y de mi señora.

ROBERTINI: Pero vos decís que era peligroso esto de la...

¿Peligroso? Re-contra peligroso.

ROBERTINI: ¿Según vos tenían la fuerza de cambiar las cosas los guerrilleros?

Sí, padre. Lógicamente tenían apoyo de afuera. Tenían un armamento de la san ostia. Era una cosa de locos, era. Ellos metían bombas en cualquier lado, atacaban, mataban. La guerrilla del ERP fue una cosa de locos. Santucho era ${ }^{11}$.

La imagen de un constante enfrentamiento en contra de la "anarquía" y de la "subversión" en la fábrica hace evidente la ideología del trabajo y la concepción de las relaciones laborales de un sindicalista de la derecha peronista (Damin, 2013). A través de la oposición al clasismo y a las agrupaciones que revindicaban la transformación de la sociedad capitalista a través de la lucha en las fábricas, se hace patente el modelo de relaciones industriales considerado como "normal" y "obvio" por parte de la derecha sindical.

En el editorial de la revista «El Caudillo», su director, Felipe Romeo, una figura clave de la represión paraestatal llevada a cabo por la Alianza Anticomunista Argentina, era aún más explícito en la definición de los «enemigos» del peronismo y de la nación:

Compañeros, la lucha es clara. Sólo existen en esto dos frentes: el de los aliados y el de los enemigos. El del pueblo y el del anti-pueblo. La Sinarquía, fuerza de la oligariquía financiera internacional, es la capagna [sic.] del frente opositor. Perón es nuestro caudillo. El que elige a sus aliados elige, al mismo tiempo, al jefe [...]. Ahora y por fin llegamos a la última y gran alternativa entre los enemigos y Perón: la destrucción o la reconstrucción ${ }^{12}$.

Las luchas internas al peronismo posteriores a la vuelta del líder en 1973 se articulan a través de una dualidad que atraviesa la sociedad argentina. Esta circunstancia es muy clara también dentro del justicialismo, donde la derecha peronista plantea una alteridad entre normalidad y anormalidad, peronismo de Perón y «drogas y homosexualidad, el mejor camino hacia la izquierda» ${ }^{13}$.

11 Entrevista a Alexander Radic (seudónimo), Tres de Febrero (prov. de Buenos Aires), 20-10-2018.

12 La Tendencia se acabó: el que manda es Perón, en «El Caudillo», n. 1, 1973.

13 Drogas y homosexualidad, el mejor camino hacia la izquierda, en «El Caudillo», n. 2, 1973. 
En lo que respecta al gremialismo, la furibunda lucha entre la derecha sindical y la izquierda clasista también se tiñó de estos tonos y, frente a la fuerza de la izquierda en las fábricas, los voceros de la derecha sindical no dudaron en afirmar la necesidad de «combatir la subversión» en el mundo del trabajo. Ese conjunto de discursos y declaraciones nos ayudan a entender el clima de época y a vincular la historia de vida de Alexander con el contexto político argentino de los 70 .

La lucha en la fábrica, escuchando la voz de Alexander, no era solamente un combate por la hegemonía sobre los trabajadores; era también un enfrentamiento entre imaginarios antagónicos. Por un lado, aquel representado por figuras icónica del sindicalismo argentino como Agustín Tosco, René Salamanca y, por el otro, el de Vandor, Ignacio Rucci y Lorenzo Miguel. El modelo de la llamada burocracia sindical se construye una vez más en oposición a las ideologías «ajenas al ser nacional», intentando recuperar un principio de paz social amparado en la doctrina social de la Iglesia (Lvovich, 2009), (Padrón, 2007), (Simonetto, 2014). La búsqueda de una solución consensual entre capital y trabajo, el respeto de la propiedad privada, pero a la vez el rechazo violento hacia formaciones de base, caracterizaba ese modelo, además de su vocación nacional.

ROBERTINI: Vos decías que cuidabas la fábrica...

Exactamente. Exactamente.

ROBERTINI: Pero eso de 'cuidar' la fábrica, ¿no quería decir hacer solamente los intereses de la empresa?

Escuchame, ipero si defendíamos más nosotros la empresa que los jefes! Los intereses de los laburantes y de la empresa también, porque nosotros comíamos de ahí. Porque nosotros comíamos de ahí. Escuchame, eso es lo que te quería contar: Tosco y Salamanca paraban diez días en Córdoba y después te mostraban el sueldo: 'mirá lo que cobramos, no cobramos nada'. Y... ¿cómo vas a cobrar? si paraste diez días tuviste la fábrica parada. Y ellos laburaban con la mente o el mensaje que le enviaban a la gente que realmente no pensaba, no pensaba la gente. 'Escuchame, estuve diez días parado ¿cómo voy a cobrar?’ La fábrica no me va a pagar, es una cosa lógica.

ROBERTINI: Y escúchame, ¿por qué Córdoba, Córdoba, digamos todo este despelote, como decías, y Buenos Aires no?

Porque Buenos Aires estaba re controlado. Por nosotros. Estaba re controlado, los que mandábamos éramos nosotros. Entonces tratábamos de alejarlo de Buenos Aires ${ }^{14}$. 


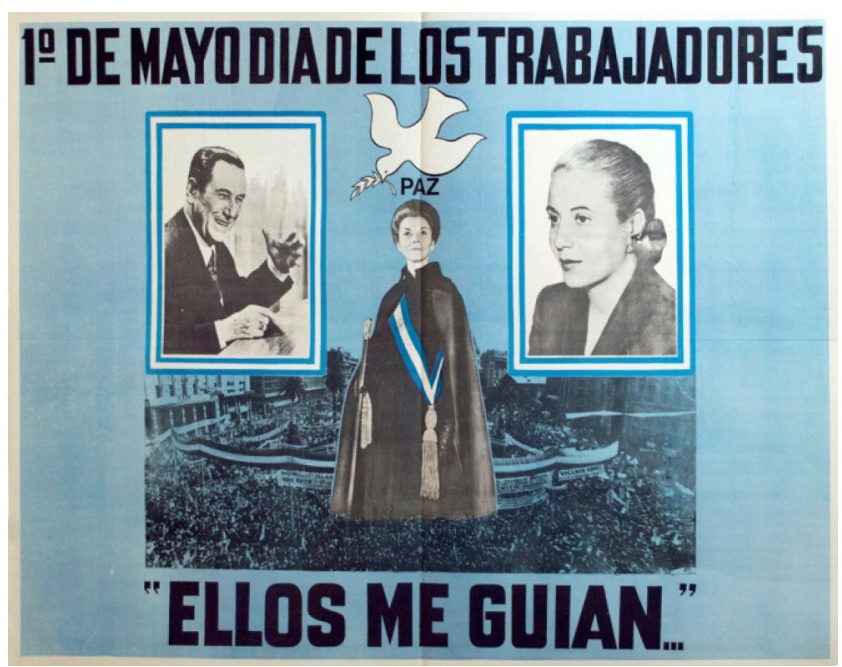

Ilustración 1. Afiche para el Primero de mayo de 1975. Fuente: Archivo del Instituto de Investigación en Arte y Cultura "Dr. Norberto Griffa", consultable en: http://archivoiiac.untref.edu.ar/index.php/ellos-me-gu (último acceso: 10-2-2020).

La idea de «cuidar a la fábrica», de ser sindicalistas «responsables» y de oponerse a cualquier plataforma antagonista hace evidente la colocación del sindicato del establecimiento automotriz en el cual opera Alexander, como de un baluarte anticomunista. Ese imaginario, tan fuerte y orgullosamente reivindicado, dialoga con los discursos y la idea de «pacto social» que fue elaborado en el contexto del tercer gobierno peronista (197376). La «responsabilidad» de los trabajadores y de sus organizaciones está representada explícitamente en un afiche (ilustración 1) en el cual todos los elementos presentes en el imaginario de la derecha sindical peronista dialogan entre sí. Podemos observar que el centro de la imagen está ocupado por la presidenta de Argentina, María Estela Martínez de Perón que, sumergida en una masa de trabajadores reunidos en la Plaza de Mayo y guiada por Juan y Eva Perón, celebra el día del trabajador.

Toda la escena está dominada por el espíritu santo y por la palabra «paz», en clara alusión al clima de enfrentamientos y de movilizaciones de la época. Alejar a las izquierdas de las fábricas, propiciar la paz social y convencer a los trabajadores para que actúen de una manera responsable son los elementos sobresalientes que definen las ideas y el pensamiento del patotero sindical.

El enfrentamiento cotidiano que se registra en las memorias de Alexander da cuenta de los objetivos de la constante acción de la patota en la fábrica: los militantes y los volantes de la izquierda. Sin embargo, se puede relevar también una fuerte aversión hacia los Montoneros que, desde su punto de vista, eran aún más culpables que la izquierda clasista, ya que dejaron la casa peronista para ir por la senda del socialismo. 
Estaba en la plaza cuando los Montoneros cantaban 'Miren, miren, miren, miren qué boludo, se casó con una muerta, se casó con una... una muerta... eh... una muerta y un cornudo'... Entonces dice, él cuenta, él cuenta que eh... 'Nos vamos padre, nos vamos de Plaza de Mayo'.

Está hablando Perón y ustedes están cantando y el pueblo está en la calle, en la calle, en la plaza está, cómo se van a ir ustedes, no son peronistas ustedes' dije.

Yo puedo coincidir que Perón los dejó estar a los Montoneros.

ROBERTINI: Pero digamos que los Montoneros querían la revolución.

Escuchame, te voy a cantar la justa. Una vuelta que agarraban el poder lo querían matar a Perón... Y hasta acá llegamos... escuchame, veníamos de una dictadura, teníamos que agarrar el poder. Lo agarramos, y se acabó... Quería otra cosa Montoneros, por eso se arma el tiroteo en Ezeiza ${ }^{15}$.

En la identidad política de Alexander, además de su filiación y completa adhesión al peronismo, podemos registrar la importancia del tema de la traición y, por ende, de la fidelidad en la construcción de los valores y de las prácticas violentas de un miembro de la derecha sindical.

\section{CONCLUSIONES}

¿Cómo se construye el imaginario reaccionario de un peronista? ¿De qué manera recuerda un protagonista de la década del 70 su participación en las organizaciones armadas? Estos interrogantes resultan fundamentales para abarcar el ámbito de estudios de la historia del trabajo que durante muchas décadas se ha referido a la izquierda clasista como al "natural" representante de los intereses obreros. De esta forma, si bien contamos con ejemplares trabajos sobre el clasismo sindical, son escasos los estudios sobre la derecha sindical peronista.

A través del análisis de la biografía de nuestro testimonio es posible reflexionar acerca de problemas y cuestiones que, si bien hacen referencia a un caso único, pueden leerse dentro de un contexto marcado por la violencia política y por la dinámicas propias de un sector del movimiento obrero. Resulta fundamental resaltar este estudio de caso ya que emergen temáticas y problemas en parte inéditos. Nos encontramos con la cuestión de las prácticas y las actitudes de la derecha sindical peronista que, si bien fueron analizadas por la literatura específica, en pocas ocasiones lograron testimonios de primera mano. Recorrer la bibliografía de un obrero común de los 70 significa acercarse a la experiencia de un sector de la clase obrera que, si bien fue poco estudiado por la historiografía, expresó una visión de las relaciones industriales de carácter anticomunista. 
Mas allá de los hechos contenidos en la entrevista, en los acontecimientos colocamos el foco en el imaginario, la mentalidad y la cultura que fueron moldeando la trayectoria de un sindicalista de la derecha peronista. Recorrer parte de la trayectoria de vida de unos de los tantos sindicalistas metalúrgicos nos sirvió para reflexionar acerca del imaginario y la identidad de la derecha sindical.

Creemos que, a través de estas páginas, la biografía del obrero peronista permite, por un lado exponer, desde su misma perspectiva, el desarrollo de los acontecimientos sucedidos entre 1955 y 1976, y, por el otro, avanzar un paso hacia el conocimiento empírico acerca de cómo se formó y cómo actuó un sindicalista de la derecha peronista en una localidad del Gran Buenos Aires.

Lejos de querer ofrecer un abordaje exhaustivo, este trabajo, a través de un caso concreto de un militante nacionalista del Gran Buenos Aires y de la adopción de un enfoque de tipo microhistórico, ha analizado problemáticas que nos invitan a retomar la apuesta de estudiar la historia reciente de Argentina también a partir del mundo de las derechas y sus culturas políticas. 


\section{BIBLIOGRAFÍA}

Águila Luciani, L., Seminara, L., \& Viano, C. (2018). La historia reciente en Argentina. Balances de una historiografía pionera en América Latina. Imago Mundi, Buenos Aires.

- La represión en la historia reciente argentina: perspectivas de abordaje, conceptualizaciones y matrices explicativas. (2013).

Albornoz C. (2019), “Combatir al comunismo sin hacerle el juego". Una aproximación a las memorias de militantes del Movimiento Nacionalista Tacuara. Ponencia, III Coloquio Internacional sobre Violencia Política en el Siglo XX y IV Jornadas de Trabajo de la Red de Estudios sobre Represión y Violencia Política (RER). Universidad Nacional de Rosario.

Bartolucci, M. I. (2017). La juventud maravillosa: la peronización y los orígenes de la violencia política, 1958-1972. EDUNTREF, Editorial de la Universidad Nacional de Tres de Febrero.

Besoky, J. L. (2013). La derecha peronista en perspectiva. Nuevo Mundo Mundos Nuevos. Nouveaux mondes mondes nouveaux-Novo Mundo Mundos Novos-New world New worlds.

- (2016a). "En la patria de Perón, ni judío ni masón". Aproximaciones a la cultura politica de la derecha peronista en los años setenta.”, en História e Cultura, vol. 5, 199-223.

- (2016b). Violencia paraestatal y organizaciones de derecha. Aportes para repensar el entramado represivo en la Argentina, 1970-1976. En Nuevo Mundo Mundos Nuevos. Nouveaux Mondes Mondes Nouveaux-Novo Mundo Mundos Novos-New World New Worlds.

- (2010). La revista El Caudillo de la Tercera Posición: órgano de expresión de la extrema derecha. Conflicto Social, 3(3), 7-28.

Bohoslavsky E., Sá Motta R., Boisard S. (2019) Pesar as direitas na América Latina, Alameda, San Paolo.

Bohoslavsky, E., \& Vicente, M. (2014). Sino el espanto. Temas, prácticas y alianzas de los anticomunismos de derecha en Argentina entre 1955 y 1966. Anuario del Instituto de Historia Argentina, (14).

Bourdieu, P. (1986). L'illusion biographique. Actes de la recherche en sciences sociales, 62(1), 69-72.

Canosa Mora, G. ““'Libres o muertos, jamás esclavos”. Marxismo, peronismo y lucha armada: las Fuerzas Armadas Revolucionarias en la Argentina de los primeros setenta." (2017).

Cerrano, C, Ghiretti, H. (2018). Nacionalismo, insurreccion armada, antisemitismo: florescencias de derecha en el ecosistema posperonista. en Trabajos y comunicaciones, 47, 1-10.

Cerrano, C. (2014). El filo-peronismo falangista 1955-1956. Ayer: Revista de Historia Contemporánea, 96(4). 
Cucchetti, H.i Derechas peronistas? Organizaciones militantes entre nacionalismo, cruzada anti-montoneros y profesionalización política. En Nuevo Mundo Mundos Nuevos. Nouveaux mondes mondes nouveaux-Novo Mundo Mundos Novos-New world New worlds.

D’Antonio, D., \& Eidelman, A. (2013). Antecedentes y genealogía de la historiografía sobre la Historia Reciente en la Argentina. Nuevo Mundo Mundos Nuevos. Nouveaux mondes mondes nouveaux-Novo Mundo Mundos Novos-New world New worlds.

Damin, N. (2013). La transformación organizacional en el justicialismo de los setenta: La Juventud Sindical Peronista (1973-1976). En, Nuevo Mundo Mundos Nuevos. Nouveaux mondes mondes nouveaux-Novo Mundo Mundos Novos-New world New worlds.

Favero, B. (2016). Las voces de una juventud silenciosa: memoria y política entre los otros jóvenes durante los años 60 (Mar del Plata-Argentina). Historia y MEMORIA, (12), 215-252.

Franco, M. (2012). Un enemigo para la nación. FCE, Buenos Aires.

Franco, M., Águila, G., Garaño, S., \& Scatizza, P. (2016). La represión estatal en la historia argentina reciente: problemas, hipótesis y algunas respuestas tentativas. Estudios/Investigaciones, 57.

James (2004). Doña María: historia de vida, memoria e identidad política. Ediciones Manantial, Buenos Aires.

- (1990). Resistencia e integración. El peronismo y la clase trabajadora argentina, 1976, 1943-1955. Siglo XXI, Buenos Aires.

Ladeuix, J. (2012). Los últimos soldados de Perón: Reflexiones en torno a la violencia paraestatal y la derecha peronista a través de una experiencia local 1973-1976. Bohoslavsky, Ernesto y Olga Echeverría (comps.) Las derechas en el Conos Sur, Siglo XX. Actas del Segundo Taller de Discusión, Tandil, Secretaría de Investigación.

Lvovich, D. (2009). La extrema derecha en la argentina posperonista entre la sacristía y la revolución: el caso de Tacuara. Diálogos-Revista do Departamento de História e do Programa de Pós-Graduação em História, 13(1), 45-61.

Manzano (2017). La era de la juventud en Argentina: cultura, política, y sexualidad desde Perón hasta Videla. Siglo XXI: Buenos Aires.

- (2010). Juventud y modernización sociocultural en la Argentina de los sesenta. Desarrollo Económico, 363-390.

Musso, S. (2015). Storia del lavoro in Italia. Il Novecento. 1896-1945 Il lavoro nella società industriale, Castelvecchi, Roma.

Padrón, J. M. (2007). Trabajadores, sindicatos y extrema derecha. El Movimiento Nacionalista Tacuara frente al movimiento obrero, Argentina (1955-1966). presentado en XI ${ }^{a}$ Jornadas Interescuelas/Departamentos de Historia, Tucumán.

- (2007). Trabajadores, sindicatos y extrema derecha. El Movimiento Nacionalista Tacuara frente al movimiento obrero, Argentina (1955-1966). presentado en XI ${ }^{a}$ Jornadas Interescuelas/Departamentos de Historia, Tucumán. 
Passerini, L. (2007). Memory and Utopia: the Primacy of Inter-subjectivity. Routledge. Portelli (2007). Storie orali. Racconto, immaginazione, dialogo. Donzelli, Roma.

- (2017). El uso de la entrevista en la historia oral. Anuario de la Escuela de Historia, (20), 35-48.

Robertini, C. (2019). Quando la Fiat parlava argentino. Una fabbrica italiana e $i$ suoi operai nella Buenos Aires dei militari. 1964-1980. Le Monnier, Firenze.

Sánchez Recio, G. (2002) "El sindicato vertical como instrumento político y económico del régimen franquista.” Pasado y memoria, no 1, 2002; pp. 19-32.

Sigal, S., \& Verón, E. (2003). Perón o muerte. Eudeba, Buenos Aires.

Simonetto, P. (2014). El caudillo de la tercera posición. Aproximaciones a la cultura de la derecha peronista (1973-1975). Sociedad y Discurso, (26).

Soto Carmona, A. (2006). "No todo fue igual: cambios en las relaciones laborales, trabajo y nivel de vida de los españoles, 1958-1975." Pasado y memoria, N. 5 (2006); pp. $15-43$.

Torre, J. C. (2012). Ensayos sobre movimiento obrero y peronismo. Siglo XXI, Buenos Aires.

Van Der Linden (2019). Trabajadores y trabajadoras del mundo, Buenos Aires, Imago Mundi.

Zicolillo, J. (2013). La era de los culatas: la derecha peronista y el patoterismo sindical. Vergara, Buenos Aires. 